\title{
Idiopathic REM Sleep Behavior Disorder in Young Adults and Quantitative Analysis of Polysomnography
}

\author{
Han A Kim, Su-Hyun Han, Sang-Ahm Lee \\ Department of Neurology, Asan Medical Center, University of Ulsan College of Medicine, Seoul, Korea \\ 젊은 나이에 발생한 렘수면행동장애와 정량적 분석을 통한 진단적 접근 \\ 김한아, 한수현, 이상암 \\ 울산대학교 의과대학 서울아산병원 신경과학교실
}

\author{
Received October 10, 2014 \\ Revised December 10, 2014 \\ Accepted December 23, 2014 \\ Address for correspondence \\ Sang-Ahm Lee, MD \\ Department of Neurology, \\ Asan Medical Center, \\ University of Ulsan \\ College of Medicine, \\ 88 Olympic-ro 43-gil, \\ Songpa-gu, Seoul 138-736, Korea \\ Tel: +82-2-3010-3445 \\ Fax: +82-2-474-4691 \\ E-mail: salee@amc.seoul.kr
}

\begin{abstract}
Rapid eye movement sleep behavior disorder (RBD) is a sleep disorder characterized by loss of muscle atonia during REM sleep associated with dream enactment, which usually start at the age of older than 50 . $\mathrm{RBD}$ in elders are known to be developing symptoms of neurodegenerative disorders in the course of disease. However, the pathophysiology and prognosis of "early-onset" idiopathic RBD is unclear. Several existing standard value about REM sleep without atonia (RSWA) of RBD patients was established with "late-onset" RBD for those diagnosed at age 50 and greater, RSWA metrics in "early-onset" RBD patients diagnosed prior to age 50 years have not been previously described. Therefore, we report here two patients who were diagnosed as "early-onset" idiopathic RBD, and performed quantitative RSWA scoring. We suggested that "early-onset" idiopathic RBD has different etiologies the various characteristics of RSWA than adults with RBD.

J Sleep Med 2015;12(1):18-22
\end{abstract}

렘수면행동장애(rapid eye movement sleep behavior disorder, RBD)는 렘수면 동안 정상적으로 발생하는 골격근의 무긴장증(atonia)이 소실되어 꿈 내용을 행동화하는 질환이 다. ${ }^{1}$ 기존 연구들에 의하면 $\mathrm{RBD}$ 는 대부분 고령에서 발생하 는데, 한 연구에 의하면 평균 58 74세에 발생한다. ${ }^{2}$ 렘수면 행동장애는 특별한 원인을 찾을 수 없는 특발성(idiopathic) 과 $\alpha$-synucleinopathy 등 다른 질환과 연관되어 나타나거나 약물의 사용 혹은 중단으로 유발되는 등 원인이 발견되는 증 후성(symptomatic)으로 나눌 수 있다. 증후성 RBD는 50세 이상에서 발생하는 경우에 파킨슨병(Parkinson's disease), 루이소체 치매(dementia with Lewy bodies), 다발성 신경계 위축증(multiple system atrophy) 등 신경퇴행성 질환(neurodegenerative disorder)과의 관련성이 있어 많은 연구가 이 루어지고 있다. 장년층에서 특발성으로 발생하는 $\mathrm{RBD}$ 의 경

This is an Open Access article distributed under the terms of the Creative Commons Attribution Non-Commercial License (http://creativecommons.org/licenses/by-nc/3.0) which permits unrestricted non-commercial use, distribution, and reproduction in any medium, provided the original work is properly cited.
우에도 시간이 지나면서 $50 \%$ 까지 신경퇴행성 질환으로 진 행된다는 연구가 있어 장년에서의 특발성 $\mathrm{RBD}$ 는 대개 상기 질환들의 전구 증상으로 여겨지기도 한다. 반면, 어린 나이 에 발생하는 증후성 $\mathrm{RBD}$ 의 경우 약물 요인이 배제된다면 대부분 기면증(narcolepsy)과 동반된 경우들이다. 하지만 아 직 젊은 환자에서 특발성으로 발생하는 $\mathrm{RBD}$ 에 대한 보고는 많지 않으며, 고령에서의 RBD가 퇴행성 질환과 연관되듯이, 젊은 환자의 특발성 $\mathrm{RBD}$ 를 장기적으로 추적할 때 어떠한 병태생리학적 과정의 전구 증상으로 볼 수 있는지 등에 대한 연구도 충분히 이루어지지 않았다. ${ }^{3}$

국제수면질환분류 기준 2판(International Classification of Sleep Disorders, 2nd edition)에 의하면 렘수면행동장애의 진단에 수면다원검사 소견이 필수적이며, 수면다원검사에서 렘수면 동안 근긴장도의 증가가 관찰되어야 하고, 병력에서 수면과 관련된 손상을 줄 수 있는 행동이 있거나 수면다원검 사에서 비정상적인 렘수면이상행동이 관찰된 경우에 진단할 수 있다. 하지만 이러한 진단기준에는 렘수면무긴장소실 
(REM sleep without atonia, RSWA)에 대한 정량적인 정보 를 제시하지 않고 있다. 이에 대하여 RBD 환자에서 RSWA 의 특징에 대하여 조사하고 RSWA의 진단적인 판정기준치 (cut-off value)를 제시하기 위한 여러 연구가 진행되었고, ${ }^{4-7}$ 최근 우리나라에서도 $\mathrm{RBD}$ 환자들을 대상으로 수면다원검 사상 RSWA의 정량적인 판정기준치를 제시한 연구가 있었 다. ${ }^{8}$ 그러나 이러한 연구들은 모두 중장년층에서 발생하는 특발성 혹은 증후성 렘수면행동장애 환자를 대상으로 한 것 이어서, 연구 결과에서 나온 정량적 판정 기준치를 젊은 나 이에 발생하는 특발성 렘수면행동장애의 진단에 사용할 수 있을지는 아직 알 수 없다.

이에 저자들은 젊은 나이에 특발성으로 $\mathrm{RBD}$ 가 발생한 두 명의 환자를 관찰하였고, 환자들의 수면다원검사에서 RSWA 를 정량적으로 분석하여 중장년층에서의 판정 기준치와 비교 하였으며, 이에 대한 국내 보고가 드물기에 보고하고자 한다.

\section{증 례}

\section{증 례 1}

34세 남자 환자가 20년 전부터 보인 수면 중 이상행동으 로 본원에 내원하였다. 배우자에 의하면 수면 중 누군가와 싸우는 듯 주먹을 휘두르거나 소리를 지르는 등의 이상행동 이 일주일에 2 3회 이상 목격되었으며, 이상행동이 심할 때
는 간혹 보호자가 맞기도 하였다고 한다. 이상행동은 꿈의 내용과 관련되어 나타나기도 하였다. 낮 동안의 과도한 졸림 이나 탈력발작(cataplexy) 등의 기면증을 의심할 만한 임상 증상은 관찰되지 않았다. 환자는 클라이네펠터증후군(Klinefelter syndrome)으로 결혼 후부터 임신을 위해 몸에 바르는 테스토스테론 호르몬 제제를 사용 중인 것 외에 다른 약제는 복용하지 않고 있다. 동반하고 있는 내과적, 신경과적 질환 은 없었고 인지기능도 정상이었으며 이학적 및 신경학적 이 상소견도 보이지 않았다. 수면다원검사에서 수면구조는 수 면 1단계(N1 stage)가 38.5분(8.1\%)으로 증가하였으며, 수면 3단계(N3 stage)는 27.0분(5.6\%)으로 감소하였다. 무호흡-저 호흡지수(apnea-hypopnea index)는 7.1/h로 가벼운 수면 무 호흡증을 보였고, 무호흡, 저호흡, 코골이, 호흡노력관련각성 (respiratory effort-related arousal) 등과 관련된 각성지수(arousal index)는 총 $0.4 / \mathrm{h}$ 로 높지 않았다. 수면 중에 과격한 행동이나 소리 지르는 모습은 관찰되지 않았으나, 렘수면 때 턱근에서 긴장도가 증가한 것(RSWA)이 여러 차례 관찰되 었다(Fig. 1). 이 환자에서 관찰된 RSWA를 긴장성(tonic)과 위상성(phasic)으로 구분하여 정량적으로 조사한 후 총 렘수 면 시간 중 비율을 계산하였다. 렘수면 시간은 총 144.5 분이 었고 위상성 근긴장도 증가는 9.5 분으로 $6.6 \%$, 긴장성 근긴 장도 증가는 9 분으로 $6.2 \%$ 였다.

긴장성 근전도는 30 초 에폭(epoch) 단위로 분석되었다. 배

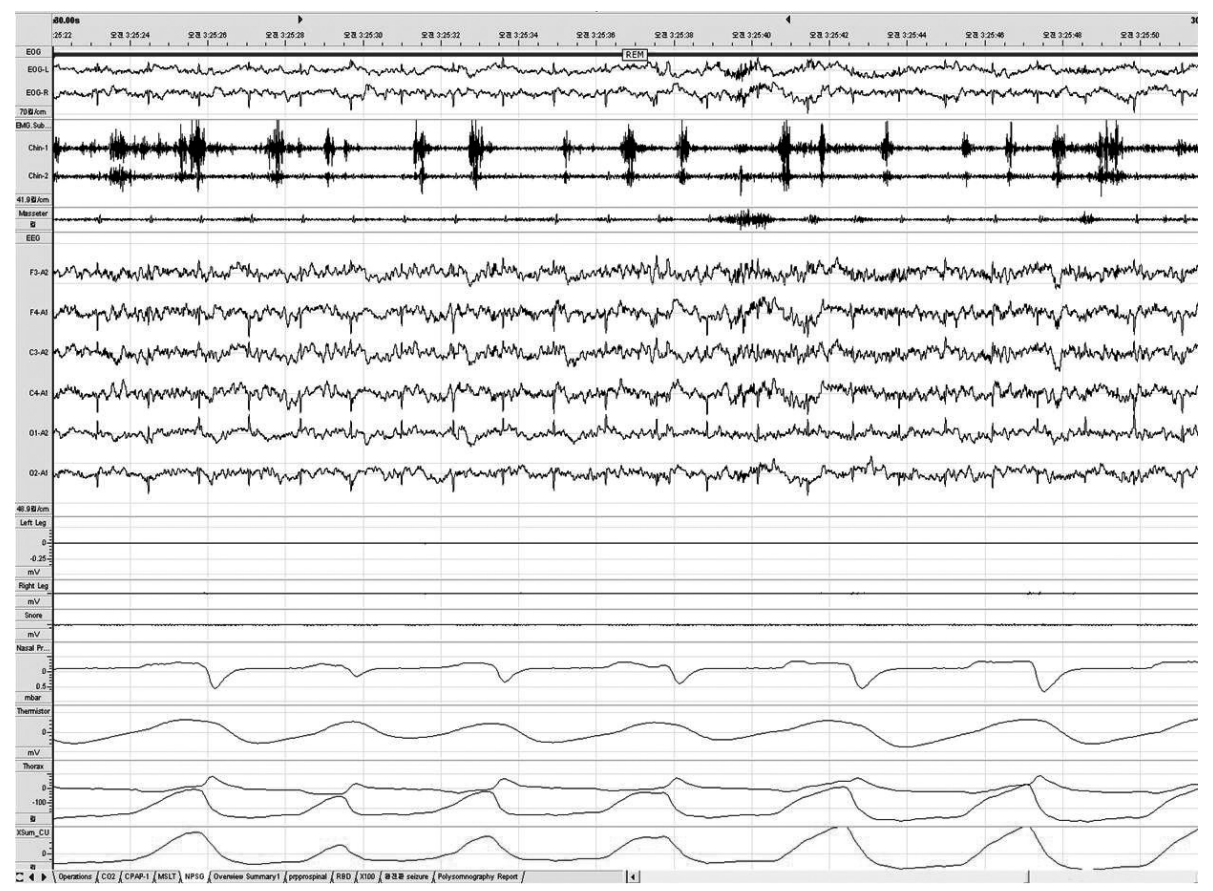

Figure 1. Polysomnography finding during REM sleep of case 1 patient. This figure shows one $30 \mathrm{~s}$ epoch. There were bursts of EMG lasting between 0.1 and $5.0 \mathrm{~s}$ where the EMG amplitude was more than four times the background EMG amplitude. EMG: electromyogram, REM: rapid eye movement. 
경 근전도 진폭(background EMG amplitude)은 렘수면 근처 에폭에서의 근전도 진폭을 기준으로 정해졌고, 30초 에폭의 절반 이상에서 근전도 진폭이 배경 근전도 진폭의 최소 두 배 이상일 경우 '긴장성 활동(tonic activity)'으로 분류하였다. ${ }^{5-7}$ 위상성을 정의하기 위해서 30 초의 에폭을 3 초의 소단위 에폭 (miniepochs)으로 나누어 분석하였다. 각 3초의 소단위 에폭 은 배경 근전도 진폭의 4 배 이상 진폭이 증가하여 0.1 5.0초 동안 지속하는 순간이 한 번이라도 있을 경우 '위상성 활동 (phasic activity)'이 있는 것으로 분류하였다. ${ }^{5-7}$ 우리 병원의 판정 기준치(cut off value)는 긴장성 활동에서 6.5\%(민감도 $94.1 \%$, 특이도 $93.3 \%$, receiver operating characteristic (ROC) curve 아래 영역 0.976)였고 위상성 활동에서 9.5\%(민 감도 $94.1 \%$, 특이도 $93.3 \%, \mathrm{ROC}$ curve 아래 영역 0.992) 였다. ${ }^{9}$

\section{증 례 2}

30세 여자 환자가 수년 전부터 수면 중에 꿈을 꾸면서 팔 과 다리를 휘두르고, 소리를 지르거나, 벽에 머리를 박는 등 의 이상 행동이 발생하여 내원하였다. 문진시 낮 동안의 과 도한 졸림이나 탈력발작 등의 기면증을 의심할 만한 증상은 관찰되지 않았다. 과거력 및 동반 질환은 없었고, 복용 중이 거나 복용하다 중단한 약물도 없었다. 이학적 및 신경학적 이 상소견도 보이지 않았으며, 뇌 자기공명영상에서도 구조적 인 이상은 없었다. 수면다원검사에서 수면 구조는 수면 1단 계(N1 stage)가 52.8분(12.3\%)으로 증가하였으며, 수면 3단계
(N3 stage)는 14.0분(3.3\%)으로 감소하였다. 무호흡-저호흡 지수는 $0.2 / \mathrm{h}$ 로 수면 무호흡증의 증거는 없었다. 이 경우에 도 비디오에서 과격한 행동이 보이지는 않았으나 턱 긴장도 의 증가가 렘수면 중에 관찰되었고(Fig. 2), 이를 정량적으로 분석하였을 때 위상성 근긴장도 증가 3.7 분, 긴장성 근긴장 도 증가 1 분으로, 총 렘수면 시간이 92 분과의 비율이 위상성 근긴장도 증가 $4.0 \%$, 긴장성 근긴장도 증가 $1.1 \%$ 로 확인되 었다. 이후 클로나제팜 $0.5 \mathrm{mg}$ 을 자기 전 한 번 투약하면서 환자의 증상은 호전되었다.

\section{고 찰}

이 두 환자의 경우 수면다원검사상 실제 이상행동을 관찰 하지는 못하였지만, 병력 청취상 수면 중 폭력적이고 위험한 행동이 관찰되고 꿈의 내용이 행위로 표현되었으며, 수면다 원검사에서 RWSA가 확인되어, 국제수면질환분류 기준 2 판 에 근거하여 RBD로 진단할 수 있었다. 두 환자 모두 기존에 알려진 RBD 발생 나이보다 훨씬 어린 10 20대에 발병하였 으며, 기면병이나 약물과 같이 증후성 $\mathrm{RBD}$ 를 시사하는 소견 이 없어 젊은 나이에 발병한 특발성 렘수면행동장애(young onset idiopathic RBD)로 진단하였다. 첫째 증례의 경우 테스 토스테론 제제를 사용하였으나 결혼 이후 임신을 목적으로 몸에 바르기 시작하였으며, 수면 중 이상행동 증상이 발생한 것은 그 이전이므로 약에 의한 영향을 고려하기는 어렵다.

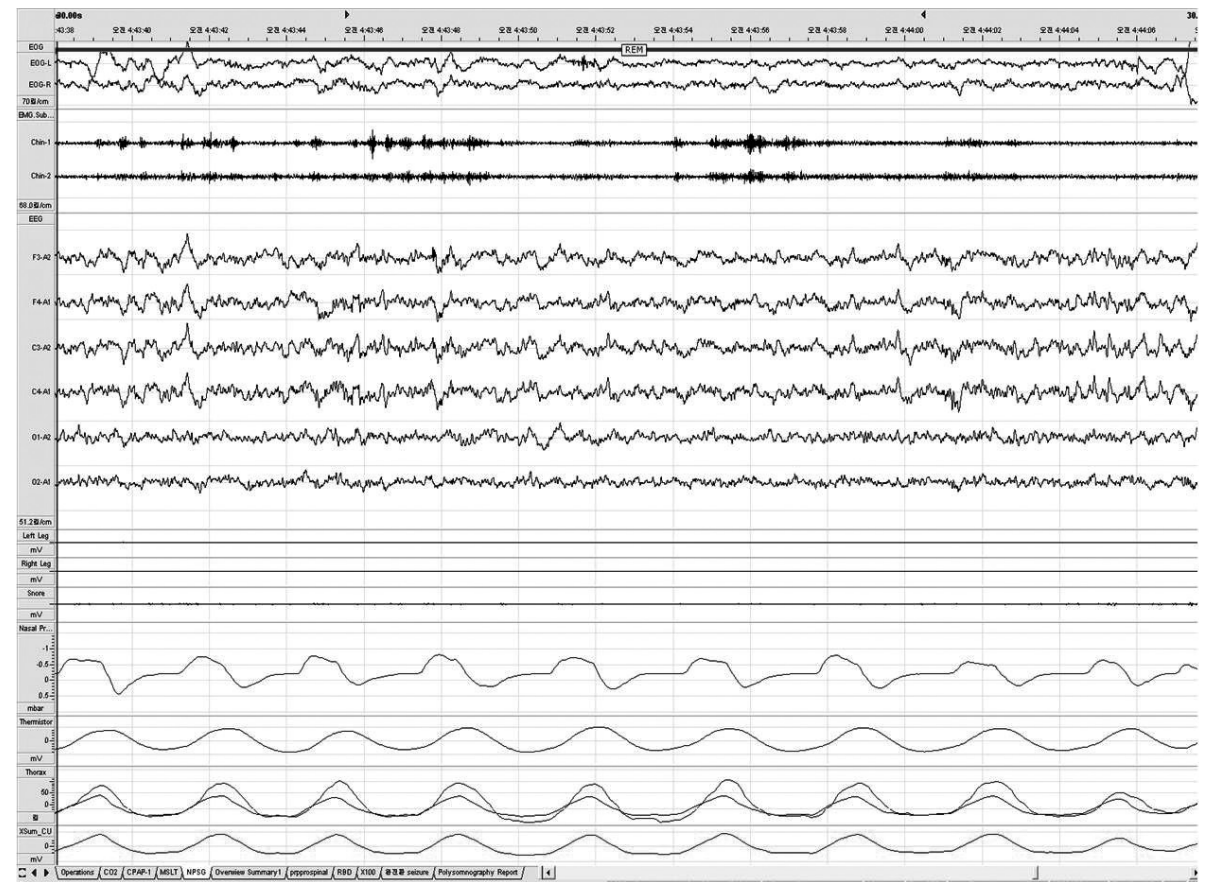

Figure 2. Polysomnography finding during REM sleep of case 2 paitent. This figure shows one $30 \mathrm{~s}$ epoch. In tonic phase of REM sleep without atonia, continuous elevation of electromyogram amplitude is observed over half of total epoch. REM: rapid eye movement. 
여기서 보고한 두 증례와 같이 사건수면(parasomnia)이 발생할 경우 감별해야 할 질환으로는 $\mathrm{RBD}$ 뿐 아니라 야간발 작(nocturnal seizure), 몽유병(sleep walking), 혼돈각성 (confusional arousal) 등이 있다. 환자가 뇌전증 과거력이 있 을 때, 반복적이고 정형화된 발작이 있을 때, 렘수면과 비렘 수면을 가리지 않고 발생하거나 비슷한 발작이 낮에도 보일 때, 그리고 항뇌전증약으로 호전될 때 뇌전증 증후군을 의심 할 수 있다. 우리 환자들에서는 이와 같은 모습을 보이지 않 아 뇌전증 증후군에 의한 증상일 가능성은 떨어진다. 또한 몽유병이나 혼돈 각성과 같은 각성장애도 $\mathrm{RBD}$ 와 감별이 필 요한데, 두 질환 모두 수면다원검사상 비렘수면에서 발생하 고, 임상적으로 우리 환자들과 구분되는 특징적인 행동을 보 이므로 진단적 가능성은 떨어진다.

특발성 $\mathrm{RBD}$ 라고 할지라도 시간이 지나면서 신경퇴행성 질환이 발병하게 되는데, Schenck 등은 특발성 $\mathrm{RBD}$ 로 생각 되었던 환자 26명을 약 16년간 추적한 결과, 21명(80.8\%)에서 파킨슨증(parkinsonism) 혹은 치매가 발생했음을 보고하였 다. ${ }^{10}$ Postuma 등은 RBD 증상 시작 후 5년에는 $17 \%, 10$ 년에 는 $40 \%, 12$ 년에서 $52 \%$ 의 환자에서 이러한 퇴행성 질환이 발 병하는 것으로 보고하였다. ${ }^{1}$ 그러나 Schenck 등의 연구에서 대상 환자들의 평균 나이는 $57.7 \pm 7.7$ 세였으며, ${ }^{10}$ Postuma 등 의 연구에서도 평균 나이는 65.4 세로 고령이었다. ${ }^{1}$ 특발성 $\mathrm{RBD}$ 가 신경퇴행성 질환 특히 파킨슨 증후군의 전구 증상일 가능성이 높다고 추정되지만, 젊은 $\mathrm{RBD}$ 환자의 경우 병태 생 리나 예후에 대한 연구는 찾아보기 어렵고 신경퇴행성 질환 의 발병도 고령에서와 달리 흔하지 않다고 보고되어 있다. ${ }^{2,3}$ 다만, 젊은 환자에서 발생하는 $\mathrm{RBD}$ 의 경우에는 기면증과 많 은 연관성이 있다는(38\%) 보고가 있다. ${ }^{3}$ 기면증 환자에서는 모노아민핵(monoaminergic nuclei)에서의 하이포크레틴(hypocretin)의 활성화가 정상보다 감소되는데, 이것이 렘수면에 주요한 것으로 생각되는 부위인 콜린성뇌줄기(cholinergic brain stem)와 기저전뇌신경세포(basal forebrain neuron)에 영향을 주어 렘수면 동안 이상 소견이 나타난다. 결과적으로 $\mathrm{RBD}$ 와 탈력발작, 낮 동안의 과도한 졸림 증상이 함께 나타 날 수 있다. ${ }^{3}$

하지만 우리 두 환자는 기면증이나 신경퇴행성 질환의 증 거 없이 젊은 나이에서 특발성으로 $\mathrm{RBD}$ 가 발생하였는데, 이는 이 환자들에서 발생한 RBD가 기존에 알려진 것과 다 른 기전에 의할 가능성이 있음을 시사한다. 실제 최근에 보 고된 $\mathrm{RBD}$ 역학조사에 따르면, ${ }^{2} \mathrm{RBD}$ 가 기존연구들보다 더 젊은 나이에 발생하고, 신경퇴행성 질환과의 동반도 더 적었 으며, 증후성보다는 특발성이 많았다. 저자들은 이러한 특징 을 보이는 $\mathrm{RBD}$ 환자들을 기존에 알려진 $\mathrm{RBD}$ 인 고령에서
발생하며 신경퇴행성 질환과 연관된 $\mathrm{RBD}$ 나 기면증과 관련 되어 젊은 나이에 발생하는 $\mathrm{RBD}$ 와 다른 분류로 나눌 수 있 음을 시사하였다. ${ }^{2}$ 또한, 이러한 환자들은 이미 알려진 병태 생리학적 기전들과 다른 기전이 작용할 것이라 추측하였고, 이 중 자가면역 질환의 가능성도 언급하였으며, 앞으로 이에 대한 연구의 필요성을 제시하였다. ${ }^{2}$ 우리 증례도 이처럼 기 존에 알려진 것처럼 고령에서 신경퇴행성 질환과 연관되거 나 젊은 나이에서 기면증과 연관되어 발생하는 RBD와는 다 른 분류로 설명할 수 있지 않을까 생각한다.

한편 우리 환자들은 수면다원검사상 실제 이상행동을 보 이지 않았다. 그래서 RSWA를 정량적 분석하여 기존에 발표 된, 근긴장도의 정량적 판정 기준치에 합당한지 비교하였다. 이전의 우리 연구에서는 17 명의 $\mathrm{RBD}$ 환자군과 15 명의 대조 군으로 진행한 연구에서 긴장성 근긴장도 증가 $6.48 \%$, 위상 성 근긴장도 증가 $9.52 \%$ 이상일 경우 $\mathrm{RBD}$ 를 충분히 진단할 수 있다는 결론을 내렸다. ${ }^{9}$ Consens 등은 신경퇴행성 질환을 가지고 있어 $\mathrm{RBD}$ 발생 위험성이 있는 환자들을 대상으로 정 량적 분석을 하여, 긴장성 근긴장도 증가와 위상성 근긴장도 증가가 $10 \%$ 이상일 경우를 RBD 진단기준으로 제시하였다. ${ }^{4}$ Montplaisir 등은 특발성 RBD 환자를 대상으로 긴장성 근긴 장도 증가 $30 \%$ 이상 또는 위상성 근긴장도 증가 $15 \%$ 를 진단 기준으로 제시하였으며, ${ }^{5}$ 그 외 특발성 $\mathrm{RBD}$ 와 파킨슨병 환 자를 대상으로 하여 긴장성 근긴장도 증가 $9.6 \%$ 이상 또는 위 상성 근긴장도 증가 $16.3 \%$ 를 진단기준으로 보는 연구도 있 다. ${ }^{6}$ Khalil 등은 특발성 $\mathrm{RBD}$ 와 신경퇴행성 질환과 연관된 $\mathrm{RBD}$ 를 대상으로 정량 분석하여, 긴장성 근긴장도 증가 $3.2 \%$ 이상과 위상성 근긴장도 증가 $1.2 \%$ 를 진단기준으로 보았는 데, ${ }^{7}$ 이에 따르면 두 증례의 환자들을 RBD로 진단할 수 있다. 최근 국내에서 보고된 바로는 5\% 이상의 RSWA를 RBD의 진단기준으로 제시하기도 하였다. ${ }^{8}$ 한 논문에서 주어진 기준 치를 제외하고는, ${ }^{7}$ 두 환자를 RSWA의 정량적인 분석으로 $\mathrm{RBD}$ 로 진단하기에는 합당하지 않지만, 현재까지 제시된 여 러 RSWA의 진단적인 판정기준치들을 바로 우리 환자들의 $\mathrm{RBD}$ 진단에 적용하기에는 아직 한계점이 있다. 첫째, 기존 의 정량적 판정기준치 연구의 대상 환자가 50 세 이후의 특발 성 $\mathrm{RBD}$ 환자이고, 이런 환자는 많은 경우에 퇴행성 질환으 로 넘어가기 때문에 이러한 환자에서 정한 정량적 기준이 우 리 환자들과 같이 젊은 나이에서 특발성으로 발생한 환자의 진단에 적용할 수 있는지 알 수 없다. 둘째, RSWA의 정량적 인 면에서 현재까지 명확한 기준이 설정되어 있지 않으며 기 준을 설정하기 위한 방법론 또한 일정하지 않은 실정이다.

본 저자는 기면증이나 탈력발작의 증거가 없는 특발성 $\mathrm{RBD}$ 두 증례를 통해 젊은 환자에서 발생하는 $\mathrm{RBD}$ 가 이전 
과 다른 기전에 의할 가능성이 있음을 제시하였고, 정량적 분석에서도 기존과 다른 판정기준치의 필요성을 주장하는 바이다. 조기발병형 파킨슨병 환자(young onset Parkinson's disease)들처럼 젊은 나이에 발병한 특발성 $\mathrm{RBD}$ 의 경우 기 존의 퇴행성 질환에서 동반되는 $\mathrm{RBD}$ 와 질병의 경과 및 예 후, 치료 과정에 차이가 있을 수 있으므로 이에 대한 체계적 인 연구가 필요한 시점이다.

\section{REFERENCES}

1. Postuma RB, Gagnon JF, Vendette M, Fantini ML, Massicotte-Marquez J, Montplaisir J. Quantifying the risk of neurodegenerative disease in idiopathic REM sleep behavior disorder. Neurology 2009;72:1296-1300.

2. Ju YE, Larson-Prior L, Duntley S. Changing demographics in REM sleep behavior disorder: possible effect of autoimmunity and antidepressants. Sleep Med 2011;12:278-283.

3. Bonakis A, Howard RS, Ebrahim IO, Merritt S, Williams A. REM sleep behaviour disorder (RBD) and its associations in young patients. Sleep Med 2009;10:641-645.

4. Consens FB, Chervin RD, Koeppe RA, et al. Validation of a polysom- nographic score for REM sleep behavior disorder. Sleep 2005;28:993997.

5. Montplaisir J, Gagnon JF, Fantini ML, et al. Polysomnographic diagnosis of idiopathic REM sleep behavior disorder. Mov Disord 2010;25: 2044-2051.

6. Frauscher B, Iranzo A, Gaig C, et al. Normative EMG values during REM sleep for the diagnosis of REM sleep behavior disorder. Sleep 2012;35:835-847.

7. Khalil A, Wright MA, Walker MC, Eriksson SH. Loss of rapid eye movement sleep atonia in patients with REM sleep behavioral disorder, narcolepsy, and isolated loss of REM atonia. J Clin Sleep Med 2013;9: 1039-1048.

8. Park SG, Shin DJ, Park HM, Lee YB, Shin DH, Park KH. Diagnostic approach with quantitative anlysis of polysomnography in REM sleep behavior disorder. J Korean Sleep Res Soc 2012;9:46-51.

9. Lee SA, Kim CS, Cho CU, Kim B, Lee GH. Quantitative EMG criteria for diagnosing idiopathic REM sleep behavior disorder. Sleep Breath 2015;19:685-691.

10. Schenck CH, Boeve BF, Mahowald MW. Delayed emergence of a parkinsonian disorder or dementia in $81 \%$ of older men initially diagnosed with idiopathic rapid eye movement sleep behavior disorder: a 16-year update on a previously reported series. Sleep Med 2013;14:744-748. 